\title{
Kazimierz Ajdukiewicz on the concept of the world- view and the rationality of religious beliefs
}

\author{
Dariusz Lukasiewicz ${ }^{1}$
}

(c) The Author(s) 2016. This article is published with open access at Springerlink.com

\begin{abstract}
The aim of the paper is presentation and critical analysis of Kazimierz Ajdukiewicz's concept of the world-view. Ajdukiewicz's philosophy was strongly inspired by the rationalism of Kazimierz Twardowski as well as by some ideas of the Vienna Circle. However, in contrast to the latter's logical empiricism, Ajdukiewicz could be interpreted as holding that beliefs constituting our world-view have both logical value and cognitive content-they cannot be construed as mere expression of some emotions.
\end{abstract}

Keywords Belief $\cdot$ Ethics $\cdot$ Religion $\cdot$ Rationalism $\cdot$ World-view

The aim of this paper is to present Kazimierz Ajdukiewicz's views on the concept of world-view and rationality of religious beliefs. ${ }^{1}$ The following presentation is closely related to his "unity thesis", formulated by Ajdukiewicz himself who claims that there are close connections among the basic philosophical disciplines: epistemology, metaphysics, and ethics. ${ }^{2}$ It is worth noting at this point that the

\footnotetext{
${ }^{1}$ Kazimierz Ajdukiewicz is regarded as one of the most prominent representatives of the Lvov-Warsaw School (Cf. "[Ajdukiewicz] is our most eminent philosopher of the last century" (Jadacki 2013, 459).

2 Though the problem of the world-view does not belong to the leading subjects considered by the most eminent representatives of the Lvov-Warsaw School, Kazimierz Twardowski, Tadeusz Czeżowski, Tadeusz Kotarbiński, Józef Maria Bocheński and Kazimierz Ajdukiewicz wrote on the topic (Brożek 2011).
}

Dariusz Łukasiewicz

darek.lukasiewicz@interia.pl

$1 \quad$ Bydgoszcz, Poland 
unity thesis provides further evidence of the great influence Franz Brentano and Bernard Bolzano exerted on Polish philosophy. Both thinkers renewed some classical ideas in nineteenth century philosophy one essential feature of which was the close connection of basic philosophical disciplines. Such a non-reductive approach to philosophy was rejected by the positivist movement, pragmatism as well as Marxism, all of which shared an anti-metaphysical and anti-philosophical orientation. A short synthetic look at Ajdukiewicz's concept of world-view will enable us, in the next part of the paper, to understand better his ideas concerning religious beliefs.

\section{Logical rationalism}

Perhaps the best way to describe Ajdukiewicz's philosophical views in a synthetic way, as well as the views of the School founded by Kazimierz Twardowski to which Ajdukiewicz belonged, is by saying that the program of the Lvov-Warsaw School was similar in some respects to logical positivism. To be sure, the LvovWarsaw School was not a Polish version of the Wiener Kreis, nevertheless, it did espouse to some extent a number of important positivist assumptions, viz., that many (but not all) metaphysical controversies were due to the semantic vagueness of language and careless use thereof (Woleński 1989, 298). In addition, they held the view that scientific orientation of philosophy is possible only if philosophical language is precise and clear and philosophy itself does not include any unjustified beliefs.

It was Ajdukiewicz who in 1934 coined the term "logical anti-irrationalism" as the name for this philosophical program [Pearce and Wolenski (1987) used another label, "logical rationalism", to express the main idea of the School]. The main idea of logical rationalism was that philosophical investigations should be carried out with the help of modern logic. Logic, however, was meant to be not only an efficient tool for doing science and philosophy, but it also had a social, political, and even existential meaning. The social and political meaning of logic, and of logical culture in particular, was that logic could help to stop proliferation of irrational doctrines which might inspire various kinds of evil in human and social life. This intellectual project alluded to a classical view defended already by Socrates according to which anyone who thinks logically will act in a morally right way. The argument has it that someone who thinks logically will know what is morally right, and someone who knows what is morally right will act in a morally right way. If this project of logical rationalism were realized in the world, human societies would lead peaceful lives free from conflicts and wars. Tadeusz Czeżowski, another eminent pupil of Kazimierz Twardowski, expressed this faith in the power of logic as follows:

A society whose members represent high logical culture becomes unanimous and united not by external force but by logic which saves it from passions and disintegration. (Czeżowski 1969, 190) 
Logic and logical rationalism - apart from its social importance-had also an existential meaning. Someone who holds justified beliefs and holds them with the assertive force proportional to the degree of their justification will do no harm to himself or others. In turn, someone who does no evil will live a happy life provided that other unexpected factors lying beyond his control will not destroy his life. And if there is a person who dedicated his life to scholarly activity, i.e. an activity which implements logical rationalism, then such a person will live the noblest life accessible to a human being (Ajdukiewicz 1985a, 316). Ajdukiewicz himself expressed the idea of the social and existential importance of logical culture as follows:

By spreading logical culture, we prepare the foundation for a scientific worldview and by doing this we enable development (Ajdukiewicz 1985b, 142).

Thus, the Polish logical rationalists from Twardowski's School held ideas related not only to the Wiener Kreis, but also to Aristotle, who regarded theoretical contemplation of eternal truths as the greatest happiness possible for humans.

However, contrary to the Austrian and German positivists, the Polish philosophers, though they believed in logic, did not reduce philosophy to logic or to the logical analysis of scientific language. This is evident in the foregoing unity-thesis that connections obtain among three basic philosophical disciplines: metaphysics, epistemology, and ethics (Ajdukiewicz 1973, 160). It follows from this that philosophy cannot be reduced only to a useful tool of formal and natural sciences.

\section{Ajdukiewicz's conception of world-view}

When developing his argument for the unity thesis, Ajdukiewicz, first of all, pointed out the relations between a world-outlook and ethics. Ethics as a normative discipline concerning human actions is founded upon evaluations, i.e. axiological propositions. There are two kinds of axiological propositions which are morally important for human beings: eudemonic evaluations and moral evaluations. The subject matter of eudemonic evaluations is the value we attach to actions and objects when we consider them from the point of view of their capacity to bring us happiness (Ajdukiewicz 1973, 162). Moral evaluations in turn point to norms and duties which we should follow and fulfill in order to be in agreement with morality (Ajdukiewicz 1973, 162). Evaluations are based on feelings (emotions or "emotional reference"). Axiological propositions are-like propositions based on sense perception-true or false, justified or unjustified, and since they are fallible, they can be verified (Ajdukiewicz 1985a, 347).

It is an interesting point in Ajdukiewicz's conception of emotions that he claims that there are no pure emotions, i.e., emotions lacking some conceptual or intellectual input. This is so because our emotions pertaining to a given object depend upon our knowledge thereof (Ajdukiewicz 1973, 162-163). In the case of eudemonic and moral evaluations, it is knowledge composed of our most general beliefs regarding the world as a whole and human beings in particular which really 
matters. We call such a set of beliefs a world-view. In brief, we can say that, according to Ajdukiewicz, evaluations are based on emotions and emotions are shaped and motivated by a world-view. In this way ethics is dependent on a worldview.

In Ajdukiewicz's view, it is important that a world-view be unshakeable and unchanging, because it guarantees stability of moral evaluations and moral judgments, which people maintain and which have direct influence on the quality of social and political life. A given world-view is ultimate and unshakeable-as K. Ajdukiewicz believed-if its thought-horizon is broad and sufficiently rich. A thought-horizon is simply a set of all beliefs which we hold or which we would be ready to accept as true and our own. A world-view is a subset of a thoughthorizon and this subset is circumscribed by its role in giving rise to moral and eudemonic propositions. A world-view can be provisional and limited or ultimate and large. It is provisional and limited if axiological propositions change when the horizon is enlarged (Ajdukiewicz 1973, 162). A world-view is ultimate if any broadening of its thought-horizon entails no revision of eudemonic and moral evaluations. Such an ultimate world-view is a guarantee of the stability of moral judgements and the predictability of individual and social actions.

Next, if we take into consideration how a world-view comes into being, we can divide world-views into two basic kinds: those acquired uncritically from a tradition (for example, a religious world-view) and those formed critically in the course of our own reflection.

There are at least three important features of Ajdukiewicz's theory of worldview which make his conception quite original and interesting. Firstly, Ajdukiewicz's emotional theory of axiological experience is rooted in his doctrine of radical conventionalism. According to the latter, there are no experimental data independent of a conceptual apparatus (Woleński 1989, 206). It is not possible to separate conceptual and empirical components of our world-view: evaluations are based on emotions but emotions depend on knowledge which we have about the object evaluated.

Secondly, Ajdukiewicz's theory of world-view is a cognitive theory in the sense that a world-view, as composed of beliefs which have a logical value, can be a description of the world. Such a cognitive and descriptive theory of world-view was typical of all representatives of the Lvov-Warsaw School and stood in opposition to the non-cognitive conceptions of Wilhelm Dilthey and Georg Simmel. Dilthey and Simmel regarded world-views as the expression of individual personality, which should not be evaluated in terms of logic as true or false, or in epistemological terms as rational or irrational, but only in terms of psychology as "authenthic" or "inauthentic".

Thirdly, in Ajdukiewicz's construction of a world-view it is epistemology which plays the crucial role. This is so because epistemological considerations lead to metaphysical conclusions which have direct importance for axiological evaluations. The meaning of Ajudkiewicz's epistemology for his conception of a world-view involves two points. The first point was that-according to his epistemological analysis - the only really and properly existent world is the world of our experience. 
The second point was that there is no world which can be a bearer and source of values other than the world of our experience.

However, we must keep in mind that Ajdukiewicz held, along with other members of the Lvov-Warsaw School and in contrast to logical positivists, a broad notion of experience. This broad notion of experience embraces sense perception (extraspection) as well as inner perception (introspection) and axiological experience (including moral and aesthetic experience). The experience of values given in feelings (emotions) is a foundation of eudemonic and moral evaluations which are essential elements of ethics.

The philosophical realism and empiricism defended by Ajdukiewicz played a crucial role in his theory of world-view as well as in his own world-view. The idea was that if everything that really exists is given or can be given in our (broadly conceived) experience, then a world-view should be built on science. Science is our best device to attain knowledge about the world of experience. Thus, an ultimate world-view should be built on science and only such a world-view can guaranteebecause of the vastness of its thought-horizon - the stability and integrity of ethics. Solid ethics in turn can contribute to the moral integrity and predictability of actions of individuals and societies.

The foregoing has been a sketchy presentation of Kazimierz Ajdukiewicz's idea of world-view. ${ }^{3}$ This idea can also be regarded as an exemplification of his unity thesis mentioned at the beginning of the paper. Epistemology implies metaphysical conclusions which belong to a world-view or are part of its thought-horizon, and a world-view "determines" or shapes feelings (emotions) on which, in turn, eudemonic and moral evaluations are based. In this way epistemology is a foundation of metaphysics and ethics.

\section{Ajdukiewicz's own world view}

Ajdukiewicz tried to be neutral when discussing different world-views-whether based on religion, on Marxist philosophy, or on spiritualist metaphysicsnonetheless he did show sympathy with some views and pointed to the weaknesses

\footnotetext{
3 One may wonder whether Ajdukiewicz's ideas regarding the world-view are of interest and relevance today. The concept of world-view is hardly on philosophers' agendas today having been replaced by other concepts such as 'scientific paradigm', 'Denkstile', 'social constructionism', 'episteme', etc. It is true that the world-view understood as the most general theory of the world lost its meaning for philosophers, the majority of whom do not believe in any 'grand narrative' (Jean-François Lyotard's term). However, one should keep in mind that even if the concept of world-view is somewhat forgotten by philosophers today, it is still important elsewhere. The term 'world-view', translated from German Weltanschauung, is still in use by non-philosophers-in common language as well as in psychology, sociology, and in cognitive science. The importance of great monotheistic religions (Islam, Christianity, Judaism) and religious beliefs in the global world is unquestionable - they impose their own world-views. Furthermore, also in philosophy there is what we could label a new grand narrative called "naturalism", which is a comprehensive theory of the world based on science. It seems that Ajdukiewicz's concept of the scientific world-view can be regarded as a counterpart of naturalism in contemporary philosophy. Thus, the worldview is a concept which does refer to something important and valued; on the one hand, there are religious world-views rooted in great monotheistic religions and, on the other, we have naturalism, which is a scientific world-view.
} 
of others (Woleński 2003, 8). Hence, it is possible to say something not only about his idea of a world-view but also about his own world-view, at least in a general way. First of all, as mentioned above, he recommended a scientific world-view and not a world-view based on religion. He wrote that:

If he [the metaphysician] takes an empiricist position in regard to the source of knowledge and a realist one in regard to the limits of knowledge, he will see no need or even possibility of seeking a world-view other than that provided by science as based on experience. If he inclines towards an aprioristic position, or even more, if he is convinced by the arguments of irrationalists, he will seek his world-view in an aprioristic way, or he will appeal to intuition or mystical experience (Ajdukiewicz 1973, 166-167).

Ajdukiewicz himself subscribed to realism in regard to the limits of knowledge and to empiricism in regard to the source thereof. He was also quite explicit that ethics should not be based on metaphysical premises such as God, the freedom of the will, and immortality of the soul (Ajdukiewicz 1973, 159). A normative ethics which does not derive its norms and principles from metaphysics is called "independent ethics". When discussing some metaphysical problems arising from investigating nature (determinism, finalism, mechanism) and religion (God's existence, divine providence in the world, the freedom of the will, and immortality of the soul), Ajdukiewicz suggested clearly enough that there are metaphysical propositions (let us call them theistic beliefs or, more generally, religious beliefs) bearing on God, the immortal human soul, and the freedom of the will, understood in a libertarian and non-compatibilist way, though they are not sufficiently justified. If we take into consideration a number of his short remarks about these metaphysical propositions, we could say that Ajdukiewicz regarded some theistic beliefs not only as unjustified but unclear as well-due to the vagueness and mutability of the concept of God (Ajdukiewicz 1973, 157). However, I do not think that he was ready to regard them as nonsensical in the way logical positivists did. In order to support this interpretation, let us consider some possible objections to the view that Ajdukiewicz's stance could be described as agnostic.

Someone could argue that Ajudukiewicz regarded theistic beliefs as lacking any factual meaning but possessing an emotional meaning. This would be consistent with the positivist approach to metaphysics, according to which metaphysical propositions (theistic beliefs included) are not entirely nonsensical since they have an emotional sense. Nonetheless, they have no cognitive meaning because they cannot be verified by any valid (scientific) experience. In support of the emotional interpretation of the value of theistic beliefs, one could resort to Ajdukiewicz's description of religious feelings connected with metaphysical concepts. Having discussed various concepts of deity occurring in different monotheistic religions, Ajdukiewicz writes:

What then is the content of the concept of God common to all monotheistic religions? What remains, it seems, is only the emotional content: the highest enthusiasm and respect, humility and submissiveness (Ajdukiewicz 1973, 152) 
Thus, the "emotional content" could be regarded as the meaning of theistic and religious beliefs. If this were the case, theistic and religious beliefs would be neither true nor false.

My point is that such an interpretation is not consistent with other views defended by Ajdukiewicz. First, Ajdukiewicz, as we know, believed in the cognitive character of axiological beliefs: eudemonic and moral beliefs have cognitive sense, they refer to objective values, and are true or false. Logical positivists rejected the cognitive nature of axiological propositions. Thus, they have for Ajdukiewicz both a factual and an emotional sense. Why not treat metaphysical beliefs based on religious experiences (mystical experiences) in the same way? Second, Ajdukiewicz defended the classical theory of truth. Propositions which are not contradictory and, therefore, necessarily false can be true or false. The last idea can be expressed in the language of modern semantics by saying that every non-contradictory proposition has its model. The truth of the proposition is not reducible to empirical verification or justified assertability. In other words, a proposition is true or false regardless of whether it can be verified by any experience. The only problem which we meet here is that we do not know whether propositions are true or false because we have no indubitable criteria of truth (Cf. Ziemińska, in this issue). Thus, Ajudkiewicz's position in regard to theistic beliefs would be a kind of agnosticism rather than the emotivism put forward by the positivists.

Someone could still object to the above interpretation of Ajdukiewicz's standpoint on religious beliefs by saying that theistic beliefs are neither true nor false because they lack any factual meaning-and they cannot have any factual meaning at all. The reason for the latter could be that the concept of God is not clear enough and it is mutable; therefore, propositions including this concept have no definite sense. However, it seems that Ajdukiewicz's conclusions, drawn from his analysis of the content of the concept of God in all monotheistic religions (Judaism, Islam and Christianity), viz., (a) there is no common factual, descriptive content of this concept, and (b) the concept has no cognitive content at all, are not sufficiently convincing. In regard to (a), we can observe that all three religions claim, for example, that God is a person, that God is the Creator of the world, God is omniscient and omnipotent. How could it be that all these monotheistic propositions have no common content? In regard to (b), we could say that even if (a) were true, it would not entail the truth of (b). Even if basic theistic beliefs concerning the divine nature had no common content, which I do not think is true, they surely have some content. If, say, divine omniscience is understood differently in Judaism, Islam and Christianity, it does not follow that we are not dealing with still the same concept of divine omniscience whose extension is divine knowledge. In other words, even if the concept of God is not unambiguous, it is still possible to construct a class of possible interpretations of propositions including this concept in such a way that every interpretation will be unambiguous. Naturally, Ajdukiewicz is perfectly aware that such an operation is possible. He writes that:

All through these attempts to give the traditional concept of God a more explicit content philosophers did not mind if, in making the content more 
explicit, they departed from the original, highly emotionally charged, concept of deity (Ajdukiewicz 1973, 154).

Thus, theistic beliefs can be formulated in a more precise way, and they have not only an emotional but also a cognitive content. However, the position defended by Ajdukiewicz is that if the concept of God is constructed in a formally better way (so that its content is precise and clear enough), then it loses its emotional sense. If the concept of God has an emotional sense, it does not have any cognitive sense, and if it has a cognitive sense, then it has no emotional sense. But why should this be so? If religious people, Ajdukiewicz seems to suggest, do not understand to whom they pray, they nevertheless pray truly, authentically, and they feel "the highest enthusiasm and respect, humility and submissiveness". But suppose that they acquire more conceptual and propositional knowledge about God, such as, for example, the kind of knowledge expressed in theological books. If this happens, according to Ajudkiewicz, they could stop feeling "the highest enthusiasm and respect, humility and submissiveness". This position appears somewhat strange and surprising, because it is Ajdukiewicz himself who, as said above, argued for the inseparability of emotional and cognitive components of axiological experience. Why in the case of religious experience is the situation so completely different? This position is not only surprising but, I think, untenable as well. It is so for the simple reason that if a person understands that a being to whom he prays is the omnipotent Lord and Creator of absolutely everything (meaning that God can do whatever he wants), then it is psychologically highly probable that he will feel "the highest enthusiasm and respect, humility and submissiveness".

Thus, a believer gains knowledge about his deity by and through religious feelings just as an independent ethicist gains his moral knowledge by and through moral emotions. Of course, propositions based on religious experiences are as true or false as moral propositions based on moral feelings.

Summing up, the most coherent interpretation of Ajdukiewicz's view on theistic and religious beliefs in general outlined thus far seems to be agnosticism: theistic beliefs have logical values: they are true or false, but we do not know these and we do not have sufficiently justified knowledge regarding the transcendent and supernatural world. The last claim could also be supported by Ajdukiewicz's remarks on the proofs of God's existence. He observes, following Kant, that the main theistic proofs (cosmological, ontological, teleological) are not sound and valid. But, of course, even if it is true that proofs are not valid, it does not follow that the thesis that God exists is obviously false. According to the classical theory of truth, to which Ajdukiewicz subscribed, the truth of a proposition is not equivalent to its provability: a proposition can be true even if it cannot be proved.

The last possible objection to my interpretation of Ajdukiewicz's agnostic standpoint on religious beliefs is his metaphysical realism based on epistemological considerations. As we said earlier in this paper, he drew metaphysical conclusions from the analysis of cognition, namely, that the world given in our experience is the only existent world and the only reality. If this is the case, then there is no other world than the world of our experience and the world of our experience is identical with the world of science based on experience. In sum, there is no God, if we mean 
by God a supernatural being outside the world of science. This view is, of course, not agnosticism but simply atheism. But even if it is a plausible interpretation of Ajdukiewicz's position, or at least more convincing than the agnostic approach, then my general point that religious beliefs have cognitive (factual sense) is still valid. The point now is that theistic beliefs are false and we have sufficient epistemic evidence to take them to be false. ${ }^{4}$

\section{The problem of rationality of religious beliefs}

Ajdukiewicz's conception of a world-view and religious beliefs leads to some further questions. Let us mention four problems. The first is the problem of compatibility of properties belonging to a world-view. According to Ajdukiewicz's logical rationalism, a world-view should be rational and "ultimate". The latter characteristic should guarantee that eudemonic and moral evaluations are solid and unshakable, which is important because it guarantees the stability and predictability of human actions. Rationality is important because it helps to protect society from nonsense and falsehood (Ajdukiewicz 1973, 46). The problem is that rational (scientific) cognition cannot be ultimate. Beliefs based on rational cognition, a scientific world-view included, can be revised and replaced by other beliefs based on rational cognition. A rational attitude includes the ability to change beliefs and to strive continuously to broaden one's thought-horizon. This can naturally change a world-view, and, in consequence, change moral and eudemonic evaluations. We can speculate that in response to this remark Ajdukiewicz could say that if a thoughthorizon is large enough and its beliefs are sufficiently justified, then moral and eudemonic evaluations based on such a world-view are more solid and stable. Thus, an ultimate world-view can be rational. What's more, solidity and rationality do not exclude each other but, on the contrary, are mutually dependent.

Second, rationality of beliefs, as Ajdukiewicz stressed, consists in their being intersubjectively "controllable" and communicable (Ajdukiewicz 1973, 46). Beliefs which are not controllable are not rational. If so, and this is the core of our second doubt, close connection between rationality of beliefs and their control does not have to disqualify a religious world-outlook as necessarily irrational.

In his Problems and Theories of Philosophy, Ajdukiewicz presented some results of such control by claiming that religious beliefs are neither formulated clearly

\footnotetext{
${ }^{4}$ Ajdukiewicz's atheism - if it is a kind of atheism-is based on epistemological considerations, the best available science of his day, and on his criticism of the traditional arguments for the existence of God and immortality of the human soul. Well after Ajdukiewicz's death there developed an interesting debate in contemporary metaphysics and philosophy of religion concerning the theistic claim that God exists, referring to arguments provided by scientific knowledge. Perhaps the most interesting approach in defence of theism is the so-called 'theology of chance' which attempts to show that neither quantum mechanics in physics nor the theory of evolution in biology are in conflict with the thesis that God exists, and that He takes care of every individual human being. The most important proponents of such a view are R. D. Bartholomew and Michał Heller. Ajdukiewicz's claim that there is a conflict, or a big gap, between science and religion seems to be too strong a thesis, at least from the point of view of the theology of chance. According to the latter, chance events are part of the divine plan and providence (Łukasiewicz 2015).
} 
enough nor sufficiently well justified. ${ }^{5}$ However, if it is possible to claim rationally that religious beliefs are not clearly formulated and well justified, then it follows that they can be intersubjectively controlled, at least to a certain degree, and, therefore, that they can be rational.

There are some possible strategies how one could respond to this point. One could say, for example, that beliefs which cannot be communicated in an intersubjective way, i.e. literally, without recourse to metaphors and analogies, cannot be controlled in an intersubjective way. If they cannot be controlled because they are not expressible literally, they are irrational. In other words, intersubjective control of beliefs concerns not only their epistemic form (the linguistic form of their expression) but their content as well. Thus, the fact that we are able to assess a belief as not rational (because of its linguistic form) will not turn that belief into a rational belief. In other words, saying that a belief is not rational on linguistic grounds disqualifies the belief as rational tout court. If we say that "God is the father of all humans" we cannot control this belief because we do not know what the precise meaning of the concept of "God the father" is. We can only control the linguistic form of this belief, noting that it employs the metaphor of God the father. But when logical rationalists speak about rational control of beliefs they mean their content and not only their form. Thus, religious beliefs are irrational because of their linguistic form, which renders impossible any external, intersubjective, i.e. experiential and logical test and control of their content.

Someone could argue that at least some religious beliefs are controllable and hence rational if expressed by propositions in which the concept of God is defined precisely. Only mystical experience cannot be controlled in the way recommended by logical rationalism, i.e. controlled with respect to its content. Propositions about God could be regarded as controllable in case the concept of God is precisely defined or described without metaphors and analogies.

Ajdukiewicz's possible response to the foregoing might be that it is not the religious beliefs in themselves (formulated in a correct way) that are irrational in the sense of controllability but the behavior of a believer who asserts a given belief with a force too strong in relation to the evidence supporting the assertion. If a religious belief is asserted with a force proportional to the evidence, then such an assertion is not necessarily irrational. ${ }^{6}$ Clearly and precisely formulated religious beliefs can be weakly asserted as metaphysical hypotheses or theoretical constructions (surmises, assumptions). The theistic belief that "God exists" (provided that 'God' means a being characterized in a literal and not metaphorical way-if possible) can be regarded as a rational belief when its assertive force is proportional to its evidence. If so, it can be regarded as rational in the sense postulated by logical rationalism and defended by Ajdukiewicz. ${ }^{7}$ Nevertheless, religious beliefs could hardly be included

\footnotetext{
${ }^{5}$ Considerations concerning the rationality of religious beliefs lead us away from the main topic of this paper; I only wish to emphasize how radical Ajdukiewicz's concept of the rationality of belief is.

${ }^{6}$ We must keep in mind that here we have two meanings of rationality: rationality of beliefs and rationality of the assertion of beliefs.

7 Such a program of metaphysical investigations concerning the concept of God was undertaken in Poland by the Cracow Circle inspired by Jan Łukasiewicz and carried out by J.M. Bocheński, Fr. Jan Salamucha, Franciszek Drewnowski, and Bolesław Sobociński (Policki 2005, 45).
} 
as parts of a rational, scientific world-view. A world-view cannot be built on theoretical constructions (which are false or probably false) or hypotheses for which we have little or no supporting (intersubjective) evidence.

\section{Moral and mystical experience}

The third problem which we would like to touch upon regarding Ajdukiewicz's theory of world-view concerns the foundation of an independent ethics. It is difficult, if not even impossible, to build or dervive ethics from science and the scientific world-view. How can the egalitarian norms of the independent ethics to which Ajdukiewicz himself subscribed be derived from science or the scientific world-view? There is an answer to this question which seems quite obvious and easy from the point of view of the independent ethics defended in Poland not only by Ajdukiewicz but also by his teacher, Kazimierz Twardowski, and other representatives of the Lvov-Warsaw School, such as Tadeusz Czeżowski and Tadeusz Kotarbiński. Logical rationalists did not claim that ethics should be derived from science or from any world-view, scientific or otherwise, but that ethics should be constructed in a scientific and rational way. The method of independent ethics is experiential, much like that applied in science, i.e., moral evaluations should, and in fact are, as Polish rationalists believed, derived from axiological (moral) experience. Ajdukiewicz himself regarded feelings (emotions) as a form of experience whose objects are objective values of human actions or products of nature (beauty of a landscape) or products of human creativity (cultural artefacts). Such experiences are similar to sense perceptions (Ajdukiewicz 1985a, 346-347). Evaluations based on moral and aesthetic feelings are intersubjectively controllable and communicable (Ajdukiewicz 1985a, 346-347); for example, the meanness of a human deed is given to us as immediately as the redness of a poppy flower (Ajdukiewicz 1985a, 347). But if a deed's meanness is given to us as immediately as the poppy's redness, then the question arises whether these kinds of experiences can be articulated in a way allowing for the intersubjective control of their contents. Is John's feeling of the meanness of someone's behavior the same regarding its intensity and content as Peter's feeling of the meanness of the same person's behavior? And what is the difference in regard to communicability and objectivity between, for example, moral and mystical experiences? Ajdukiewicz considered the latter, as we noted, to be clearly irrational (Ajdukiewicz 1973, 49). He was perfectly aware that contents of sense perception or even axiological experience cannot be fully expressed, and that we often have to resort to metaphors, for example, when we describe our pain. Therefore, we resort in these cases to linguistic expressions which are only schemas and abstractions. Despite all the shortcomings of language as the expression of our immediate experience of various objects, we build our knowledge of internal and external reality on the basis of experiential data. So, we can restate our question: why are mystical experiences, in which mystics experience the existence of a deity "directly, as it were face to face", irrational, whereas the experience of a landscape's beauty can be rational? 
I think that Ajdukiewicz might answer the above question in two ways. He could say that mystical experiences happen very rarely and they differ in regard to their contents. Moreover, propositions based on them concerning divine beings are not consistent with the rest of our knowledge, with our thought-horizon embracing our scientific world-view. To assert that there is a God who is the Creator of the world on the basis of mystical experiences has much lesser degree of justification than an assertion like "Killing innocent people is morally wrong" based on feeling the negative value of such an outrageous act.

Over the past decades there has been much discussion about the rationality of religious beliefs and the nature of religious experience, mystical experience included. The so-called 'Reformed Epistemology', started by William Alston, Alvin Plantinga, and Nicholas Wolterstorff, aims to undermine the view according to which beliefs based on religious experience are irrational. On the contrary, as Plantinga put it, "it is entirely right, rational, reasonable, and proper to believe in God without any evidence or argument at all" $(1983,17)$. The proponents of Reformed Epistemology hold that religious beliefs can be properly foundational and need not be justified by other beliefs. It is beyond the scope of the present paper to discuss the premises and theses of Reformed Epistemology, let us mention only that it developed in opposition to classical foundationalism, which is a view that belief can be regarded as justified only if it is a foundational, self-evident, and infallible belief, or it is derived from such a foundational belief. Ajdukiewicz seems to follow to some extent this deeply Cartesian foundationalist tradition (Cf. Ziemińska, paper in this volume).

Taking into account the new approaches in the epistemology of religious beliefs, could we say that Ajdukiewicz's views on the irrationality of religious beliefs are old-fashioned today? It would be difficult to claim this. The very project of Reformed Epistemology has met strong criticism. Interestingly, it is criticized also from positions quite similar to those Ajdukiewicz held some seventy years ago (Everitt 2004). Reformed Epistemology is a minority view, whereas most of contemporary epistemologists and philosophers are ready to interpret religion and religious experience in a naturalistic way, coherent with the scientific method (Richard Dawkins, Daniel Dennett). Perhaps Ajdukiewicz would have easily agreed with some contemporary atheists who argue that mystical experience is simply impossible because its object is a transcendent entity (Everitt 2004). The argument has it that even if a transcendent entity (God) exists, it is beyond our capacity to experience such a being. Arguably, Ajdukiewicz would have slightly changed this line of reasoning to the effect that it is impossible to experience such a being, because there is no being beyond and outside our experience. But, in general, Ajdukiewicz's view regarding religious beliefs can be easily adopted by any contemporary philosopher who is sympathetic to the agnostic or atheist positions.

\section{Social meaning and historical context of logical rationalism}

Fourth, Ajdukiewicz demonstrated that a religious world view is closely related to such human feelings and needs as the belief in the meaning of individual life and that of the world as a whole, the belief in life after-death, the belief in the ultimate 
victory of good over evil (Ajdukiewicz 1973, 154). Ajdukiewicz did not analyze to what extent a scientific world-view satisfies all these humans desires, but, nonetheless, he was aware that materialism, for example, is unacceptable to many because of the tragic strain of this doctrine (Ajdukiewicz 1973, 125) consisting in its rejection of the immortality of the soul and its incompatibility with all religions. I think that-in this particular context-we can regard the materialistic doctrine as equivalent to the scientific world-view defended by Ajdukiewicz. Thus, for many a scientific world-view represents a tragic doctrine. However, to reiterate, Ajudkiewicz recommended its acceptance as one of the direct consequences of logical rationalism, whose social importance he described as follows:

However, the voice of the rationalist is a sound social reaction, it is an act of self-defense by society against the dangers of being dominated by uncontrollable forces such as a saint proclaiming a revelation or a madman affirming the products of his sick imagination, and finally a fraud who wants to convert others to his views for the sake of his egoistic and unworthy purposes. It is better to rely on the safe but modest nourishment of reason than, in fear of missing the voice of 'Truth', to let oneself be fed with all sorts of uncontrollable nourishment which may more often be poisonous than healthy and beneficial (Ajdukiewicz 1973, 49).

It is a very intriguing manifesto of anti-irrationalism, which taken in itself deserves a careful analysis. But it is worth keeping in mind the historical circumstances of this text. It was written in the period immediately following the end of the Second World War at the onset of the communist dictatorship in Poland. However, it is also worth noting that these words were written before the Lvov-Warsaw School was officially accused by the Polish Marxists for its solidarity with logical empiricism, objective and subjective idealism, theoretical and practical fideism, and psychologism (See for example: Schaff 1952). Ajdukiewcz's Problems and Theories of Philosophy had appeared in 1949, that is before the regime decided that several philosophers from the School (Izydora Dambska, Maria Ossowska, Stanisław Ossowski, Władysław Tatarkiewicz) be barred from lecturing at universities and others (Władysław Kotarbiński, Janina Kotarbińska, Ajdukiewicz himself, Tadeusz Czeżowski, Maria Kokoszyńska) be allowed to lecture on logic only (See Woleński 1989, 21-22). What is more, the Polish Marxists before 1949 did not engage in polemics with the School. The situation changed in the early 1950's, but already after Ajdukiewicz had proclaimed his manifesto of anti-irrationalism. So it seems rather improbable that his position was determined by the Marxist campaign against him and other members of the Lvov-Warsaw School, or by his knowledge of the Stalinist crimes. To be sure, it does not mean that his program of anti-irrationalism does not apply to the communist ideology, or that he was sympathetic with Marxism in any way.

\footnotetext{
8 Ajdukiewicz used the term 'logical anti-irrationalism' already in 1934 when describing the main trends in Polish philosophy. It is also noteworthy that in the early 1930's Ajdukiewicz witnessed race segregation and antisemitism at Polish universities (Ghetto Benches and numerus clausus, which was one of many methods used to limit the number of Jewish students who might study at a university). He, like other representatives of the School (Twardowski, Czeżowski, Kotarbiński), opposed such regulations and
} 
This historical context can explain his minimalist and, in a sense, "tragic" worldview. This minimalism can also be regarded as a kind of rationalist radicalism since it is ready, after all, not to hear the voice of "a saint proclaiming a revelation". The above manifesto of logical rationalism can also be read as a defense of freedom to search for truth as the most noble aim of human life. But we should also remember that Ajdukiewicz was strongly sympathetic to logical positivism prior to the emergence of extreme social and political movements in Poland and in other parts of Europe. However, despite his sympathy to positivism, Ajdukiewicz defended the autonomy of philosophy and understood how important a role philosophy can play in everyday life; namely, the role of providing a theoretical basis for answering the question of how to live. His theory of world-view and the unity thesis can be regarded as support for the claim in behalf of the practical role of philosophy.

Open Access This article is distributed under the terms of the Creative Commons Attribution 4.0 International License (http://creativecommons.org/licenses/by/4.0/), which permits unrestricted use, distribution, and reproduction in any medium, provided you give appropriate credit to the original author(s) and the source, provide a link to the Creative Commons license, and indicate if changes were made.

\section{References}

Ajdukiewicz, K. (1973). Problems and theories of philosophy, (trans by H. Skolimowski, \& A. Quinton). Cambridge: Cambridge University Press. [first printing in Polish 1949].

Ajdukiewicz, K. (1985). Jezyk i poznanie, T. 1, Państwowe Wydawnictw Naukowe: Warszawa.

Ajdukiewicz, K. (1985). Jezyki i poznanie, T.2, Państwowe Wydawnictwo Naukowe; Warszawa.

Ajdukiewicz, K. (1987). Der logistische Antiirrationalismus in Polen. In D. Pearce, \& J. Woleński (Eds.), 1987. Logischer Rationalismus. Philosophische Schriften der Lemberg-Warschauer Schule. Franfurt am Main:Athenäum Verlag. First printed in 1934 as Logistyczny antyirracjonalizm w Polsce, Przeglad filozoficzny, 37/4.

Ajdukiewicz, K. (2003). Zagadnienia $i$ kierunki filozofii. Teoria poznania $i$ metafizyka. Kęty: Wydawnictwo Antyk- Fundacja Aletheia.

Brożek, A. (2011). Światopogląd a filozofia-charakterystyka systematyczna. In S. Janeczek, R. Charzyński, \& M. Maciołek (Eds.), Światopogladowe odniesienia filozofii polskiej (pp. 17-19). Lublin: Wydawnictwo KUL.

Czeżowski, T. (1969). Odczyty Filozoficzne, wyd. II, rozszerzone. Towarzystwo Naukowe w Toruniu. Prace Wydziału Filologiczno-Filozoficznego: Toruń.

Footnote 8 continued

regarded the ideology behind antisemitism as wholly irrational. Ajdukiewicz was also deeply moved by Moritz Schlick's death in 1936. But I think that it would be a great mistake to associate his program of logical anti-irrationalism simply with the historical time he lived in. The postulate of anti-irrationalism was deeply rooted in the Brentanian tradition and was defended in Poland already by Kazimierz Twardowski before the First World War. In his paper of 1934 Ajdukiewicz pointed to Twardowski as the most influential proponent of anti-irrationalism in Poland (Ajdukiewicz 1987, 31). But, on the other hand, we cannot exclude that the peculiar historical events and circumstances could have inspired Ajdukiewicz to formulate in 1949 his new manifesto of anti-irrationalism. It might be useful, therefore, to distinguish between logical anti-irrationalism and social anti-irrationalism. The first would be limited to philosophy and the second would be applied to the domain of social life as well. The rationale for this could be his 1934 definition of logical anti-irrationalism. According to it, anti-irrationalism is a postulate "nur solche Sätze gelten zu lassen, die auf eine nachkontrollierbare Weise begründet sind, wodurch jede mystische Intuition oder Wesensschau ausgeschaltet wird"(Ajdukiewicz 1987, 30). It is clear that this definition is restricted to the domain of philosophy whereas the manifesto of 1949 went beyond philosophy, to problems of a historical, social and political nature (Zielinski 2013). 
Everitt, N. (2004). The non-existence of God. London: Routledge.

Jadacki, J. (2013). Twórczość i wolność w ujęciu Kazimierza Ajdukiewicza. Przeglad Filozoficzny- Nowa Seria, $n r, 4(88), 459-468$.

Łukasiewicz, D. (2015). On the argument from chance for the non-existence of God. European Journal for Philosophy of Religion, 7, 199-210.

Pearce, D., \& Woleński, J. (Eds.). (1987). Logischer Rationalismus. Philosophische Schriften der Lemberg-Warschauer Schule. Frankfurt am Main: Athenäum Verlag.

Plantinga, A. (1983). Reason and belief in god. In Plantinga \& Wolterstorff (Eds.), Faith and philosophy. London: University of Notre Dame Press.

Policki, K. (2005). Filozofia człowieka we wczesnej twórczości J.I.M. Bocheńskiego OP, Papieski Wydział Teologiczny we Wrocławiu, Wrocław.

Schaff, A. (1952). Poglady filozoficzne Kazimierza Ajdukiewicza. Warszawa: Książka i Wiedza.

Woleński, J. (1989). Logic and philosophy in the Lvov-Warsaw school. Dordrecht: Kluwer.

Woleński, J. (2003).Wstep, [in:] Ajdukiewicz (2003), 3-10.

Zieliński, A. (2013). Życie trudne, ale pogodne. Przeglad filozoficzny- Nowa seria, nr, 4(88), 21-26. 